\title{
The Architecture of Value Thinking and Pneuma in Housing Associations
}

\author{
Jan Veuger \\ Noorder Ruimte Centre of Applied Research on Area Development, Hanze University of Applied Sciences, Groningen, 9747 AS, The \\ Netherlands
}

\begin{abstract}
Housing associations make too small a contribution to society, the government has to step in too frequently because of maladministration, and the associations' executives are often unaware of the far-reaching impact of their decisions. These are the conclusions of new academic research conducted by Jan Veuger of Rotterdam School of Management, Erasmus University (RSM). In the author's dissertation, he asserts that in numerous cases, there is no correlation between social and financial objectives. The Dutch House of Representatives debated the results of the report Ver van huis from the Parliamentary Committee of Inquiry on Housing Associations in early December, 2014. The research that is being carried out at the moment is constructed in a manner that if we understand something about value thinking and what underlying motivation is, an approach can be deducted that will allow us to control them. After the introduction, an explanation of the theme of the research will be given and the choice for a four-phase model with a deepening as to what value(s) is (and are). From the perspective of the four-phase model, the emphasis will be put on the socialization and thinking capacities, and parallels will be drawn between the values within the four-phase model, the examined values, and in specific, public housing corporations.
\end{abstract}

Key words: Values, social housing associations, organization, control.

\section{Introduction}

"We can't solve problems by using the same kind of thinking we used when we created them", Albert Einstein once said. This statement characterizes examples from 2009 of possibly mismanagement within building corporations and politics, of self-enrichment, and self-overestimation. Is all the media attention coincidental and are all these cases just incidents, or are the contour of a trend emerging? Can we still rely on sensory perception, value creation, integrity and vice versa? Are (new) rules of the game sufficient to rely on? Is supervision sufficiently regulated?

\section{Design/Methodology/Approach}

After extensive exploration of the literature and Ph.D. studies on the period from 2005-2009, the research design inspired was based on the grounded theory, which has a certain bias as a result of the extensive literature study. In the line of thinking of the grounded theory, interviews with directors more or less contracted uninhibited according to a narrative method. Afterwards, these interviews, independent of the researcher, thematic and labeled by a single Delphi method should be submitted to an expert group which created a storyline. The results of this Delphi method have been submitted to a peer group of directors. Then these conclusions in a survey presented to 60 selected directors and the subsequent conclusions. There has thus been more than a triangulation of research than just interviews, Delphi method and survey. Hypotheses are thereby omitted because of the difficulty of fitting in within the chosen research design inspired by grounded theory.

Corresponding author: Jan Veuger, professor; research fields: real estate. E-mail: j.veuger@corporaterem.nl, j.veuger@pl.hanze.nl. 
3. Responsible Corporate Governance: A (Dis)illusion for Public Housing Corporations?

"Value is determined by an opinion and insight into the range of the human brain, determined by its direction, its interest, its behaviour, and is expressed in a thought form in order to satisfy a need."

Corporations are in essence not profit-driven organizations, but consciously allocate means towards societal goals. It is difficult to name these goals and to compare them with each other. Can we measure or guide them? As long as there is no objective method to compare goals, these kinds of questions are difficult to answer. There are different streams of thought concerning goals, as to what is important, as to what has priority and as to what influence can be exerted. The complexity of cooperation, of efficiently resolving problems is enormous. The difference between in- and external, long and short term is becoming smaller.

The quote by Albert Einstein "We can't solve problems by using the same kind of thinking we used when we created them" makes that managers feel at times out of balance, without knowing exactly why. Many organizational management instruments, as, for example, the Balanced Score and INK, deal with a non-active content choice, and do not deal with choice or behaviour. The risks of an instrumental and a mechanical approach of the tools are considerable. It is crucial to see which relationships are at stake and how the process of influence-taking by stakeholders in the dealings of an organization, in the decision-making as well as the implementation, can be guided. This can be done through the lens of corporate governance thinking by societally justifying, the horizontal responsibility, the vertical supervision, and value-guided management. A solid and professional style of governance is essential to social entrepreneurship. Self-guidance as a point of departure for promoting professionalism plays an important role in efficacy, efficiency, and transparency. Additional optimalizing in- and external control does not mean a new organizational infrastructure. It is about an improved integration and coordination of management methods and techniques (co-existence and tolerance) that the organization (already) uses.

The question is also whether developments surrounding a new arrangement between corporations and government will result in a solution. After all, the work is complicated, because social entrepreneurship is too complex to be able to combine different goals. Supervision would have to be external, from a board of supervisors, and in a such a manner that the board at least oversees the spectrum of the total policy, which has sufficient focus, maintains it, and heads towards the goals of the enterprise and the targets that are derived from it. The use of instruments offers possibilities, but is most definitely not a guarantee for guidance and precluding integrity. Apart from that, visitations, by which the minister could not order interventions against individual corporations, could be an important tool for the new authority. Intervention would only occur on request of the authority. It is remarkable that neither the proposal of the Commission New Arrangement between Government and Building Corporations nor the law proposal on Social Entrepreneurship, has resolved/improved everyday praxis, because it deals with behaviour. An integration of these new instruments should at least be of relevance.

\section{Ethics, Profession and Organizational Limits}

Collins [1] posits that companies - that were in a comparable situation as their competitors - all of a sudden accelerated and in a period of 15 years explosively grew. What differentiated these companies from others in the same sector were timeless factors: leadership, hiring the right people, continuing to see the hard facts, having an answer to three framing questions (what are you best at? What 
do you believe most in? And what is essential to your continuing economic survival?), possessing a disciplined organisation culture, attaching (selective) importance to technology, continuously and persistently working without revolutionary break-through moments. With these capacities, one can grow towards excellence. Laws have often evolved insufficiently, and allow for exceptional or unacceptable behaviour. Self-regulation can be an addition and the role model of the organization - and more importantly, that of the people - can be of critical importance. It must be noted that integrity is not facilitated by merely complying with the rules of an organization, in compliance with prevailing laws. Relativation is of certain importance, but at least as important is working on the morality of the involved professionals.

A further trend is that the contours of organizations are becoming more elusive. Thinking of chains through the walls of a company is an important theme at the moment [2]. Apart from that, a changing area of tension between competition and cooperation can be observed. When is someone a competitor and when is it possible to cooperate with someone? Do we share the same vision with regards to a common goal? Within organizations, there is often a high degree of loyalty. But what about the limits of the organization? Authority in a chain is often much more complicated and diffuse. It is also about letting go of thinking along the lines of theory that is applicable to financial and political markets. To develop a specific theory for managing and investing in real estate [3], custom-tailored to the specific characteristics of the real estate market, the different types of real estate investments and their actors are being advocated [3]. A core idea is that research and transmitting knowledge are urgently required. For the involved management, it is not possible to control processes, for which they are responsible, in such a manner that over several years, the desired results will be achieved. Understanding the value of these results is also not easy, because value manifests itself in different shapes. Until now, there has been insufficient multidisciplinary cooperation in the field of research on real estate [3]. Each of the previously mentioned sciences is relevant to real estate management. Certain demands with regards to the character of a person and his attitude towards work are asked from a professional. The following can be named: a critical attitude towards one's own performance and that of others, the willingness to carry responsibility, a high degree of commitment, taking initiatives, and striving towards greater efficiency and efficacy. A multidisciplinary character of real estate management forms a bottleneck in determining as to which insights - also with regards to their context - must be gathered.

\section{Value Thinking in the Four-Phase Model}

The four-phase model by Hardjono is in essence a framework for a common language and a tool in answering the question as to which direction an organization should head towards. The model is the result of a number of organizational principles that structure points requiring attention, possible choices and interventions. It gives the own thinking procedure of the organization a shape so that-independent of the question as to whether change is desirable-a responsible choice concerning organizational interventions can be made. The model does not, however, give an answer as to the reason of change, nor does it give an explanation as to whether a chosen approach brings about change and as to whether this occurred in a professional manner.

Hardjono first formulated the four-phase model, and wrote the dissertation: "Rhythm and organization dynamics: four-phase model with clues for organizational intervention in order to increase efficiency, efficacy, flexibility and creativity" [4]. The four-phase model is the result of several studies, theoretic models and practical experience. In particular, the model gives direction in accumulating 
competences, and can consequently answer for the actions that led stakeholders to opt for a specific choice of direction. The model, therefore, presumes that an organizational improvement occurs because different modes in management follow each other not linearly, but cyclically [5]. It is, thus, increasingly desirable that organizations are sensitive - and, thus, anticipate-towards social circumstances. Due to its scientific foundations, the idea of giving direction to competency accumulation, anticipating social circumstances and making actions more transparent, the four-phase model is the most suitable model to use as a basis for this research on value thinking and managing. And that is why the four-phase model was chosen as the basis of value thinking in this research. "Using the four-phase model is only useful if there is awareness that quality care is a matter of survival" [4].

\section{Values in the Four-Phase Model}

In the processed management theories by Hardjono [4], the sensitivity towards values is determined by a value hierarchy, which makes it possible to explain human behavior. The thoughts of Lievegoed concerning the evolution line (pioneering, differentiation and integration phases), along which organizations should evolve [6] and the cloverleaf as thinking pattern for structuring an organization [6] have influenced the four-phase model. In the reasoning of an integrated organization that the manager needs to manage and control, it stands at the centre of the organization surrounded by four, equivalent sub-systems. On these crossroads of information and communication paths, it directs processes, management through information processing and distribution, external relations and marketing, supply of resources and people [6]. In the development of the four-phase model, it has been tried to regard the evolution lines - that were worked on in the past-as a whole. In the search for values by Hardjono [6], he comes to a classification of values in four different levels, which also labeled a hierarchy of values. These values are independent of each other, but have a remarkable relationship with each other in the sense that each right of existence is assured by the presence of the precedent one. This can be well interpreted through the use of a metaphor, like the one described by Pirsig [4] of an open book in a PC (personal computer) and to transfer this metaphor to living in a home. The computer is an object made up of dead matter, and thus forms an organic value. This matter is necessary to host the hardware with which the hardware can enable the management of the software, and thus the organic value is formed. The hardware has thus become a condition for the functioning of the software, the social value. Noteworthy is that both hardware and software can exist separately, but that software cannot be used without hardware and hardware retains its value, but not vice-versa. Through giving meaning to software, intellectual value is created, with a comparable relationship as the one between software and hardware. Pirsig's value philosophy, which is located between objective and subjective values, is not the only one to attribute a hierarchical order to values [4]. Regarding the intellectual value as the highest ranking value relates to the highest possible virtue of considerations of cultural philosophers such as Hegel: the pure being, self-consciousness, reason, mind/religion, pure knowledge.

By applying a metaphor of living in a home for the value(s) of a corporation, one needs to consider the anorganic value of the stones as being necessary for the organic value of the real estate corporation. This form of management of the stones is a prerequisite for the use of the social value with which a specific applicability has been created, the value has increased and a new value was added. The stones have thus become a perquisite for acquiring a specific applicability, the social value. Noteworthy in this relation is that it can exist separately, but that the social value cannot be used without the stones. The pneuma [7] of housing can only function if the 
ensemble of stones, management and specific application possibilities operate as a whole, through which as a whole it generates a specific intellectual value.

Here, a relationship between pneuma and social value exists that is comparable to the one between management and application possibilities. Herewith, the connection is made between values, individual needs and organizations; an organization being defined as a co-operative union between individuals that are driven by their individuals needs [4]. Apart from the seven needs of Maslov, Hardjono identifies two further needs, that of knowledge and understanding. By translating this to public housing corporations, there will be no motive for an individual to be part of a corporation. The presence of pneuma is necessary for all values as organic, anorganic and social. The congruence of individual and organizational targets appears to have great attraction on the individual; by which the relevance of congruence is recognized and loyalty and commitment increase. The criticism of Maslov's theory that the hierarchy assumes a successive evolution, in which the satisfaction of the preceding level leads to the next one, is recognized by Hardjono in his four-phase model by giving attention to all forms of capacities. Sacrificing a preceding satisfaction for a higher value is considered to be unethical. The existing right of a corporation is determined by its organic value, the shape of its organization. But the question is whether the social value of specific application possibilities and the intellectual value are being recognized by its environment. The measure of direction communication in between values as well as their evolution is also recognized by Lievegoed [6] in his description of pioneering, differentiation and integration phases. The transition from one phase to another generates attention for cooperation, external orientation, serving function, and is finally directed by the intellect, with the cloverleaf as thinking pattern in the third phase of integration [6].

\section{The Value of the Four-Phase Model}

With regards to the reasoning of the four-phase model, it is important to realize that one is dealing with an interconnected whole of people that exercises an influence on each other. The organized collaborations of the expressions of the organizations in the form of power and numbers are to be interpreted as the organization. Perceptible expressions are not always rational and do need to be interconnected [4]. Through a certain degree of repetition and stabilization, it is possible to recognize a structure; one which people avoid if it does not serve their own goals. The evolution of people, that is also shaped by outside influences, thus, also forms the organization. In the context of the four-phase model, the existence of the structures is thus not neglected [4] and are, therefore, also found in the model; although Hardjono prefers to think in terms of processes. The subjectivity of the model is recognized, but through dialogues in the experience years of the model, a deepening has taken place and the model has moved in the direction of intersubjectivity. It has, thereby, not become a model of an objective description of the reality. Because the model simplifies reality, it can be criticized [4]. As Hardjono describes, the four-phase model is characterized by: "subjective knowledge as science-philosophical basis and regulated change as possibility for change" [4]; he, therefore, uses fundamental conditions, namely: (1) that human action is based on significances; (2) which result from social communication; and (3) which are handled and altered in a process of interpretation [4]. It can be assumed that if this philosophy is translated to housing, the act of living in housing only acquires value and thus significance if it is referred to in a sociological sense. Housing only acquires a position in the dealings between people if you can do something with it. The different capacities within the four-phase model do not only influence the value of the concept of housing, but depending on the orientation direction that each capacity will also 
change its form. Because of these different orientation directions, different play grounds become visible, that can be disrupted; these spaces and disruptions can change the focus of attention.

Therefore, the four-phase model can be applied as an interpretative instrument. Through the development of knowledge and thus the development of the organization within the context of value thinking within a hierarchy of values, the professional is introduced. This professional is described as "a person who with the help of creativity and application possibilities uses scientific knowledge in solving value problems" [4]. The value problem is defined here as the amplification of this value by designing, conceptualizing in advance actions, and-parallel to that - thoughts as to how these actions can be adjusted if necessary. The value of the four-phase model resides in its helpfulness to "design an intervention that solves a unique and specific problem so that an increase of value takes place" [4].

\subsection{Value Increase with the Four-Phase Model}

The question to ask is whether we must speak of value increase or value addition. Value increase presupposes that there is more of the same. In addition, on the other hand, that something is added to another, and that it does not need to be the same. Furthermore, the question can be added whether what constitutes value for whom? The questions cannot be answered without assuming which exchangeable desire is at stake. The four-phase model is composed of four different kinds of capital instead of values, because the aesthetic component that value entails can be linked to norms. In the use of the term capital instead of value, Hardjono [4] leaves the value doctrine of economic theory that has evolved into a value philosophy. Using this philosophy, it is not just a matter of an objective value judgment, but also about recognizing an absolute, eternal value outside the historical and social value awareness. In the context of the four-phase model, value is not merely seen as a significance as to whom belongs property or is entitled to it; the notion of value is also placed in the scope of this property. The question that can be asked is whether the scope of property determines the value, in relation, for example, to the market share, in the absolute sense, of the number of houses in the entire Dutch real estate market, or the exchangeability of the desire, in which the desire and the capital to make. The four-phase model, therefore, focuses on the definition of the term capital with its double meaning, i.e., the possession of property and the ability of what one is capable of doing. By speaking of property within the context of capital, it immediately becomes clear where the property is to be situated. This stands in contrast to the term value, because value has a different meaning for each individual involved, and is accordingly expressed differently.

\section{Orientation on Socialization and Reasoning Capital}

The ability to cooperate constitutes the social capital in the four-phase model which relates the most to the individual needed to be part of an organization. The organization represents for the individual the social need, and can provide the individual with this. By integrating this, one can lean on the appreciation of an individual. The socialization capital, therefore, determines how the organization determines its architecture; this genetic code can be regarded as something that can be changed. Through a mutation of the genetic code, the architecture changes, and therefore the genetic code is the key to changing.

"The reasoning capital is the collective result of personal growth and intellectual development of the members of the organization" [4], and therefore enables the organization to maintain a structure. The reasoning capital thus has a collective character and presumes that all it encapsulates all prior experiences. In the four-phase model, the reasoning capital is related to notions such as empathy, plans, insight, synergy, self-knowledge, behavioral norms, reflection 
capacity and inventivity. If we apply these notions to the developments within the world of housing corporations in the last five years - and in particular what the literature has written on this subject, a picture of corporations and their reasoning capital emerges. Without reasoning capital, it is not possible to increase the socialization capital, whilst the presence of socialization capital constitutes the basis for the reasoning capital. Due to this mutual interdependence, Hardjono posits that the reasoning capital is the source of everything. It can be observed that in the world of housing corporations, the dialogues concerning the developments and the value of the material capital - the stones, and in many the commercial (in)capacity reached above all the media, but not so much the socialization and reasoning capital. The presence of reasoning power, on the basis of societal appreciation, is referred to by Hardjono [4] as the intellectual capital, also called reasoning capital. The relation between all four capitals of the four-phase model - and in particular the way it has earlier been adapted to the housing mission, can be represented in four circles. The mutual interdependence and interchangeability is thereby expressed, and the whole can be increased; each individual condition, independence and capitals must be present.

The circles of the four value capitals - the first layer of the four-phase model, give a balance of works in different directions, and need to be in balance among each other. The capital increase finds it way along a new layer in the four-phase model, in the two axes, internal and external orientation, and forms the primary orientation directions for value increase or increase of the capital. Hardjono [4] posits that: (1) an organization needs to find a balance between internal and external orientation; and that (2) organization needs to find for itself a balance between an orientation towards control and an orientation towards change - the second layer of the four-phase model. In general, one can choose to adapt management theories for value addition or value increase [4]. Giving attention to this leads to concrete results with their own characteristics, and forms the third layer of the four-phase model. Differently formulated: if we want to understand the concrete results of housing corporations, we need to examine their orientations. A change of direction in orientation is influenced by interventions which are iterative. On the different capital levels, different interventions are possible; the condition for this is that each orientation direction gives - related to a specific capital, a specific key for intervention [4]. For the socialization and reasoning capital of housing corporations, the interventions from the perspective of orientation on change - internal and external orientation - will be more closely examined.

\subsection{Interventions in the External and Internal Orientation Context}

The housing corporations market can be regarded as an open system in which marketing procedures can be carried out on an consumer market: the external orientation. Several questions need to be questioned in this context: under which terms and conditions do we offer our houses and services? How is the social housing (Fig. 1) market segmented (and did we do this)? Who and where are our tenants? These are questions that can be answered if there is an external orientation. If these are brought into connection with the four capitals - in particular the socialization and reasoning capital, keys for interventions emerge. The creation of a network is the result of an intervention on the socialization capital, based on the external orientation. Herewith, the housing corporation learns to anticipate in the context of a social environment, and there is a greater willingness to take more risks, and entrepreneurialism is increased. The striking power of the entrepreneurialism of a corporation can come under pressure by the social setting.

The intervention of anticipating societal developments has an influence on the reasoning capital of the corporation. Empathy will have a 
positive effect on the other capitals, and will lead to plans based on strategy. Creativity becomes apparent in the form of lateral thinking [4], but can also lead to the trap of respect earning admiration with no increase in turnover. The discussions in the period of 2009 concerning the right of existence of housing corporations can be placed in this context. An extremely external orientation can lead to oversensitivity of housing corporations.

Means for internal orientation are cohesion/morality and information management/communication [4]. Cohesion can be regarded as a socialization value through the development of a social system, in which morality can also be attributed to the reasoning capital. Internally, questions such as "as how far are we corporations?" and "What is the identity of the organization and what does it contribute to the organization?", answering these questions, as well as the question how the socialization capital of a corporation can be controlled, lead to the creation of an organization with a distinct hierarchy, that eventually assigns tasks, responsibilities and competencies. Reflecting on these matters leads towards orientation on change, and contributes to the flexibility of housing corporations. The reasoning capital of the corporation can be increased internally by executing self-inquiry, which will lead to self-knowledge. Here, a certain tension between developing the reasoning capital and the external orientation can develop. By combing this self-inquiry with explanations and forecasts, the synergy within a corporation will be increased; synergy is here to be understood as the benchmark [8] for efficiency [4] with which the organization realizes how to deal with her reasoning capital. A too strong orientation of the reasoning capital can also lead to all energies being invested in this, not resulting in anything. In the period of fusions of corporations, this becomes evident in the fact that the external orientation decreases in such a period. However, through interventions on the internal orientation, a certain flexibility of the organization arises.

\section{Interventions with an Orientation on Control and Change}

One element of the economic engine is the structure of revenues and profit margin. Questions that arise in this context are: Where in the system of housing corporations are possibilities for profit to be found? Where do the margins come from? What has determined the size of the profit margins and are the most important factors influencing this? Answering these questions ought to result in a system of control, and might be able to change the said system. Through an orientation on control and should get to goal-oriented interventions. Creating a structure in a hierarchy forms a tool to assign tasks, responsibilities and compentences within the corporation and to avoid ambiguities. By influencing the yield of the social capital, the effectivity is increased. Controlling the reasoning capital thus takes place through explanations, forecasts, by qualifying the scope of the reasoning capital [4]. The flexibility and the adaptation ability are determined by answering questions such as: How alert must we be as a corporation react to value additions? How can investment programs be adapted? Where is resistance against change to be found? Such questions are related to the control of different capitals, and thus refer to the reasoning capital of the corporation and its mobilization. Insight is, therefore, a prequisite for maintaining and increasing the other capitals. An extremely advanced orientation on control leads to rigidity.

The orientation on change has an influence on the innovativity and flexibility of the corporation with creativity and flexibility as a product [4], but also has its influence on the different values. The division into two distinct concepts such as internal and external orientation creates a kind of tension; this also applies to two non-overlapping concepts such as control and change: they cannot do without each other. Total 
control does not mean being completely open to total change, and orientation on change must be seen as proof that the housing corporation is capable of true renewal in terms of consolidating and increasing its existing capital. If the corporation is capable of doing this, then this will lead to a wealthier corporation where everybody will support new developments and ideas.

\subsection{The Intellect of Solidarity, Sobriety and} Inspiration

Solidarity [9] is more than promoting specific interests on a local level or in the short term, and it is more than making donations to charitable organizations. The content of this concept is determined by the Christian social teachings that are based on a personalized notion of man; man is more than an individual and rational being that stands in relation with others. Its relevance becomes apparent if it stands in relation to others. In the context of this concept of man, the Church distinguishes two fundamental principles: first, the immutable dignity of each human being, i.e. human dignity. This dignity is inviolable and requires to be respected; The second principle is complimentary to the first; the result of collective responsibility is not a sum of different interests, but the common good. The common good is aimed at creating a society [10] into which everyone brings inviolable human dignity and truly everybody shares responsibility for others and the whole. The government needs to be involved in a continuous dialogue with the civil society to create a structure of justice, and people and groups need to create content for the common good. This emotion generates the value that must be measured.

Solidarity thus brings with it a responsibility that transcends time and space. Making responsibility explicit and the desirability of this is necessary to point out problems that derive from the mission of housing that emerge in areas with a mission. Through the availability of the financial means that wealthy corporations protected by them, through mediating problems in the best possible manner and thereby protecting their own wealth.

Every human and every generation have the right to fully participate in a society, and thus participation is a condition for solidarity, and thus a duty, apart from the right. Thus, the concept of subsidiarity-the manner of organization or rule in which tasks are assigned in to a higher level for matters that cannot be dealt with on a lower level—needs to be applied here, because personal responsibility cannot be delegated nor is it transferrable. Thus, one cannot acquit himself from personal responsibility. In the case of shortcomings of this, the higher level has the subsidiairity duty to intervene in a contributive or replacing manner. Another condition for solidarity is moderation. One can speak of a right measure, if there is the right balance between human dignity and the common good. All other interests are subordinated to this, and it must be presumed that private wishes and ambitions are to be relativized. The self-cleansing ability to contribute an indispensable piece to this responsibility is thus essential in order to make a contribution to the problems of housing. The "soul of socially responsible entrepreneurialism" lies at the core of the spirituality, the pneuma, the fourth $\mathrm{P}$ that Van Luyn introduced in 2001 and which the Social-Economic Council recognized. By inspiring people consciously and in a deeper sense, they become more connected with each other. Through inspiration and acting accordingly, people also become mutually connected with each other [4]. Without inspiration and the spirit, things does not work, and "the fire" lacks. And thereby a current of three movements of our time becomes determinative: solidarity versus individualization, sobriety versus economization, and spirituality against secularization-unchaining the spirit in which the housing mission was meant.

\section{Value Thinking}

The answer to the question as to what constitutes 
value is partially determined by the academic perspective with which one looks at value. An economist look at and defines value differently than a philosopher or a sociologist. Value thus knows many modalities, and is an indication of a relevance of something, and actually reflects how big the relevance is to a person or what relevance a group attaches to it in order to get it: $a(n)$ (real estate) object, information, a service or a right. The question is how one can look through different lenses of value-may be a new-picture as to what value is and how an interpretation can be given as to what value can be. This has been done through a number of lenses, which will be discussed in detail in the next section; the exchangeable desire is a synthesis of the different lenses. One lens that was used is the report entitled The Benefit of Values, value thinking according to the Social-Economic Council [11]. This report is the result of a question by the former cabinet concerning the growing interest in social entrepreneurialism. The other lens is by authors of Enterprise and Society [12] who used the scientific responsibility, as well as the insights from the social positions they have fulfilled. In addition to that, other lenses were used to look at value thinking in the contexts of philosophy, ethics, axiology and anthropology. Looking through the lenses of real estate and value-based management at value produces different insights. Finally, as a last lens, value thinking from the perspective of the origins of housing corporations was examined; this section is titled consistency after the self-employment. Looking through different lenses, with all its different perspectives, has generated an insight concerning exchangeable desire.

\subsection{Value and Values}

The question is whether values can be thought of outside of a context. Are their universal values that can be applied to each context, and does one need to take into account the right of existence of values? Are all values equal, or is there a pyramid of values? And will this pyramid of values be arranged differently tomorrow, and if this is the case, are we speaking about a decline or a shift in values, in which people do have a value awareness, but in which some values become more important than others? A paradigm arises by pronouncing a statement concerning value and decisions: it is not difficult to take decisions, if one knows what values are. On the other hand, one can presume that taking decisions influences the value. And taking decisions can be difficult.

Looking at entrepreneurial value and in particular the value of social entrepreneurialism, we can posit that values of companies have an external dimension value (the market) and an internal dimension value (the sum of loyalty and motivation of individuals). In his article, Jagersma [13] writes that entrepreneurial value in particular is the result of three elements: First, it is the result of the individual values of influential employees in key positions on several leading levels; second, the history of the company; and third, the context of the sector in which it operates. The most interesting aspect of his theories is that two elements are given: the history and the sector. The history is a fact that cannot be altered, and the influence of a company on its particular sector is almost impossible to measure. What remains are the influence and role of the key positions of the leading employees. They can achieve change by adjusting the direction of the hardware: organizational structure, strategy, systems and processes. But they can achieve the most important adjustments through the software: the company values. A new direction with new goals must be supported and implemented by individuals. The (new) company value constitutes a bridge function between the non-changing personal goals of individuals and the altered company goals due to change of direction. If the company values do not change, the company heads towards a treacherous pool of red numbers. The company value-determined by its individual values, is thus a raft on which the company floats. Or in the way 
Jagersma defines value and values: "Values are necessary to generate value (profit respectively shareholder value). Companies have a problem if the values of a company do not correspond with the value that is to be generated (as formulated in the company goals). Value and values are two side of the same coin that is name entrepreneurial success".

If we now look at the value definition of the fourth $\mathrm{P}$ of pneuma as acting according to the spirit, and the three different levels of the subjective, objective and absolute spirit, and apply these to the key elements of the Social Economic Council's report on socially responsible entrepreneurialism, we get to the following definition of socially responsible entrepreneurialism with value and values.

The company consciously focuses on the following four dimensions of entrepreneurial activities - profit (the economic yield), people (the consequences for people inside and outside of the environment), planet (the effects on the natural habitat), pneuma (acting in accordance with the spirit) - and thereby contributes to the long-term social welfare. This is a relation with the stakeholders that is maintained on the basis of transparency and dialogue, and in which an answer is given to justified questions asked by society.

\subsection{The Fourth Era of the Housing Corporation:}

\section{Pneuma}

The developments of an institution that was allowed by the law, such as a housing corporation, can be divided into three periods. The first one that lasted until the end of the Second World War had diverging goals:

"Housing was not just a health measure, but also pedagogic one; it concerned morality and social integration" [8].

The second period, after the Second World War, was marked by the reconstruction of the Netherlands; the government played largely the goal of director. The arrival of secretary of state Heerema marks the third period; he layed the foundation for a policy reformation with his key note on "housing the nineties". Initially, this reorganization was carried out with strength; the result was that the offer guidance of the government disappeared almost completely. One of the consequences of this was the self-employment of 1995; the ties between government and housing corporations were severed. This was done with the expectation that Heerema's trend letter of 1993 in which he announced: interest increases would generate enough means to fulfill the social mission of building and managing [8]. Van Os [14] assumes, therefore, despite the recent discussions concerning capital, supervision, governance and regulating the sector, we are still living in this third period. The critical question that can be asked here is whether we are still living in this third period, but maybe should evolve towards a fourth period, the intellectual capital. The question that Klamer asked himself [12] is whether social engagement is a new success factor, next to the three Ps of the triple bottom line: profit, people and planet. Recent developments in 2009 concerning integrity, professionalism and impact of acts result in the addition of a fourth $\mathrm{P}$, principles or even pneuma. The basis for responsible entrepreneurialism is principles such as honesty, openness and good citizenship, a legitimation or license to operate. Compassion as a binding element seems more than necessary in today's society.

\subsection{In Times of Reformation or Downturn}

In times of the reformation or downturn of a company with social real estate, a law may apply that has not been researched so far, but is generally considered to be true: the law of Gresham, that says: bad money drives out good money exchanged for the same price. This law has been added to the appendix, and is here used as a paradigm for the real estate of a social real estate company. In his work, Visser (1995: 266-268) concludes that Gresham's law offers a useful perspective for the study of a broad scale of phenomena concerning instability in economic life. 
The law does not appear to be universally valid, but Kindlerbergen (Visser, 2005) has shown that the law can be generalized in the sense that there is always the danger that the market all of a sudden does no longer accept the existing (price) conditions and that it will flee from one asset to another. The undervalued assets of, e.g., the real estate of housing corporations, is being saved and is kept as a capital object. See here also the discussion surrounding the increase of the income limit for housing corporations as a result of the competition case of corporations in the Netherlands. The relation between market weakness and rate is an application of purchasing power parity theory: if the quantity of houses in a country declines in value, then more houses are needed to purchase a specific quantity of a good or a market position, and the rate of the (weakened) house falls. Curiosity concerning the (currency) new developments makes that companies (humans) would like to maintain these new developments and will trade the old through the sale of existing property, which makes circulation more difficult. We draw here the comparison between the currency and Gresham's law. The content of Gresham's statements changed with introduction of the bi-metallic system, in which the full-valued silver and/or gold coins with a fixed price relation were

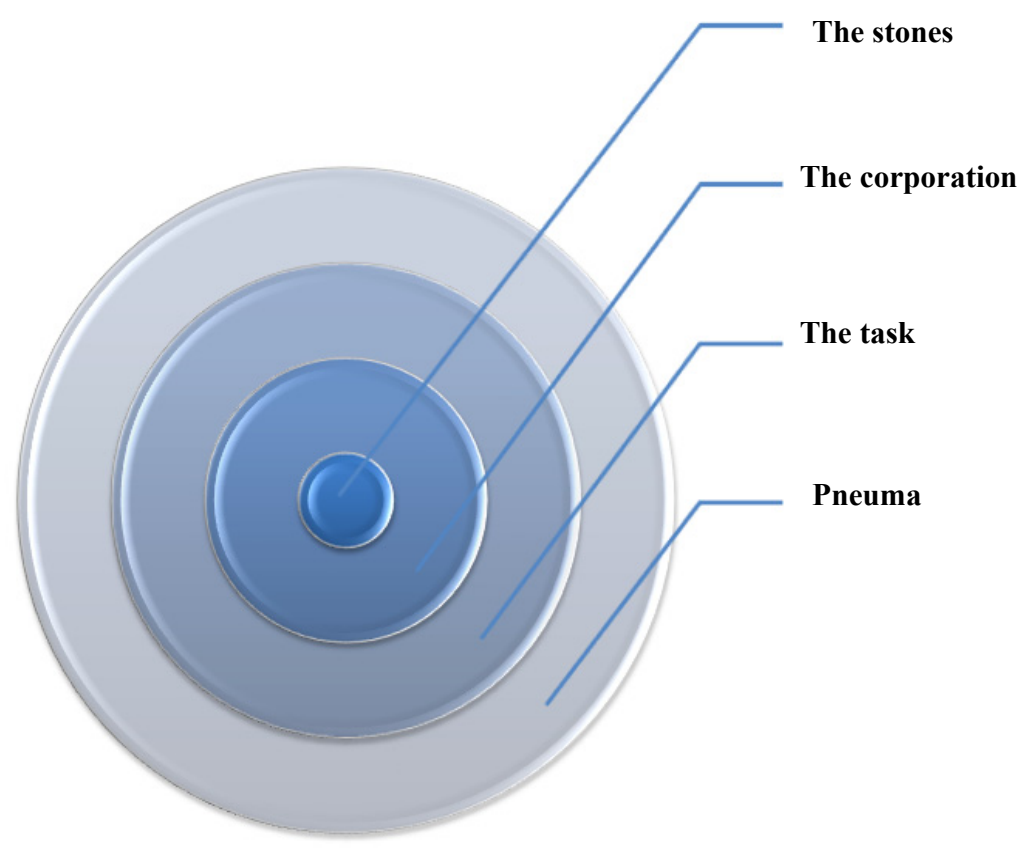

Fig. 1 Planning social housing [15].

Note: The stones (equipment capability and flexibility social property) as value driver is the material assets consist of the possession of social property and motivators like recognition and acceptance. Flexibility of the stones is in the manufacturability which is flexible and will remain;

The organization (return value, legitimacy and geographical scope) corporation as a value driver in the first instance by its geographic position and scope. The values assigned to a corporation on the basis of the capitalized results, its return value. Capitalized results are the proceeds of a given period to the value of the money that is involved;

The task (locking performance, socially conscious entrepreneurship, understood and broad orientation) is about the performance of the corporations secured, with conscious social entrepreneurship which is an important value driver. Being able to hear what the environment understanding with a broad spectrum of interests;

Pneuma (solidarity, guarantee structure, resilience and social housing policy) is leading in the principle of solidarity as enshrined in the constitution. Assurance that the housing is good or works within a structure is a float value in which they can stand up for themselves (resilience). Another value driver is the independent social housing policy that is about affordability, quality, and increase availability. 
spent and could freely be "encouraged", and price relations between gold and silver could change. One can speak here about a relatively content-rich, precious metal, the expensive money, and the cheap money that is the same as the expensive money, but with a lower metal content. In a modern economy, this only occurs during a deep crisis, such as a war or the collapse of the trust in the money that is circulating. Also, the contrary of Gresham's "good money drives out the bad" (Visser, 2005) is true, if bad money is subject to difficulty and extensive to predict erosion: the dollarization of economies that are plagued by high and fluctuating inflation. In the article by Visser (2005:267-268), the impact of a crisis is regularly brought into connection with Gresham's law. In a crisis, a situation occurs in which different kinds of money - read here the financial market of which the real estate market is a part of - are no longer regarded as equal. By exchanging en masse one kind of money for another kind, this becomes not always possible since the exchangeability is suspended. The story can be, according to Kindlebergen (Visser, 2005), the extended to the monetary sphere: it occurs when money, other financial assets and real assets exist, that can serve [14] as substitutes for each other in price relations. Of course, there is not always talk of an official price relation in which the market price relations deviate, but during a crisis, something similar occurs, namely a sudden alteration of the expectations which results in old market price relations no longer sufficing and holders, all of a sudden, considered overvalued assets wanting to get rid of their property. Kindlebergen focuses mainly only crises and instability. Gresham's law in its reformulated version thus says "Two monies are unstable over time since the weak one drives the stronger into hoarding". Furthermore, Kindsbergen posits that, in order to contain the consequences of a crisis, a tender of last resort is necessary, without completely letting go completely of price relations. In his approach, the emphasis has shifted from different currencies/real estate to portfolio management of economic subjects, and therefore Gresham's law becomes a useful tool for the historic economist.

\section{Conclusion: Inspiration and Exchangeable Desire}

The most visionary thought can be determined with information resource and giving direction to the organization. The four-phase model works here in a supportive manner, and can thereby increase different values of an organization. Because "if an organization wants to survive, it will need to be visible in or anticipate the affairs that occur in a society" [4]. The metaphor of living in a house as the value(s) of a housing corporation is the anorganic value of the stones as matter necessary to incorporate the organic value of the housing corporation. This form of managing the stones is a prerequisite condition for the use of the social value; herewith, a specific application possibility is created, through which the value has increased and new value has been added. The stones have become a condition for creating a specific application possibility, the social value. Noteworthy in this relationship is that they can exist separately from each other, but that the social value is useless without the stones. The pneuma of social housing can only exist if the whole of stones, management and specific application possibilities operates as a whole; then a particular intellectual value is formed. The final steering process takes place on the level of the intellect; in this process of the transition towards the different phases of pioneering, differentiation and integration, attention is created for cooperation, external orientation and a serving function. Knowing and understanding as a desire next to other primary desires can be translated to housing corporations by realizing that when they no longer satisfy the primary relevance of social housing that then, there is no more reason for the individual to be part of the corporation. People will avoid the structure of the corporation if 
their individual goals are not served. From the philosophy that human actions are based on significances that result from social communication and that are modified in a process of interpretation, it can be assumed that housing only acquires a value - and thus, significance, if it is referred to in a sociological sense. The value of the object housing can be influenced by orientation direction with the four-phase model, and can, with this model, change the form of each capital; in this way, different playing areas become apparent, and in return, each space and breakthrough can shift the focus of attention. The presence of each capital and the mutual dependence as a interconnected whole is necessary for the personal and intellectual growth of people within the corporation; the reasoning capital as the source of everything becomes a prerequisite for success. If we want to understand the concrete results of housing corporations, then we must look at what the orientations have been. The reasoning capital of the corporation can be increased internally by introspection, which in return will result in self-knowledge. By combining this self-knowledge with explanations and predictions, the synergy within the corporation will be increased, and the flexibility of the corporations will be created. In addition to the reasoning capital, influencing the yield of the socialization capital can increase the effectivity.

Solidarity thus brings about a responsibility that transcends time and space. Explicating this responsibility and the desirability of it is necessary to point out the problems that result from implementing the social housing mission that result from areas with a mission. Through the possession of financial means the wealthy corporations have and that are protected by them by accommodating their problems in the best possible manner and thereby protecting their own wealth.

Herewith, the concept of subsidiarity - the way of organizing or the rule in assigning tasks that a higher level employs because they cannot be dealt with on a lower level-is applicable, because the own responsibility cannot be delegated and is not transferrable. One can thus not withdraw oneself from personal responsibility. In the case of shortcomings, the higher level has the subsidiarity duty to act in an assisting or replacing manner. One can speak of the right measure if there is a right balance between human dignity and common good. All other interests are thus subordinated, and it can be assumed that personal desires and wishes are relativized. The self-cleansing ability to contribute an integral to this responsibility is thus essential in solving problems in the social housing context. The soul of social entrepreneurialism resides in the spirituality or the pneuma of social housing as spirit in which the social housing mission was invented. The pneuma is thus not just a metaphor for describing human uniqueness, but also a description for a particular energy/dynamism underlying reality. The fourth era of the corporation can thus be qualified as one that is concerned with the maintenance, renewal and restoration of the original goals.

The critical question that can be asked here is whether the corporation has already arrived in the era of the pneuma, or whether it still needs to evolve towards this era in order to survive. In the period between 1950-2008, the spirit of the social housing has inhabited the institution called housing corporation. In times of crisis, a situation in which different opinions are no longer regarded as equal occurs within the housing corporation. Wanting to massively transform one opinion into another does not always work, because the exchangeability is abolished. By looking at housing corporations through the eyes of Kindlebergen, the following picture emerges. We are dealing with intellectual capital, money, other financial assets and real assets that exist and can be used as substitutes for each other in (price) relationships. Of course, there is not always talk of an official (price) relationship in which market relationships are diverging, but something similar occurs in a crisis, namely a sudden 
divergence in the expectations through which existing (market price) relationships no longer suffice and those that hold suddenly overvalued assets want to get rid of their possessions or their thoughts. In order to curtail the impact of a crisis, a tender of last resort is necessary, without letting go of the relationships. In this approach, the emphasis can be shifted from different opinions to portfolio management. The composed concept of social entrepreneurialism that it implicates entails - because of the financial and social yield - an implicit conflict, that can be prevented by admitting foreign capital with interest - and not only from a financial perspective - and not pay a return on investment. The legitimation should be derived from the field in which the corporation works and is responsible to, instead of the mechanism of national, political democratic control. The law on housing formulates a destination duty for the capital that a corporation manages and assigns the task of taking care for good and affordable housing; the government holds a large share of the decision power concerning how that capital is to be spend. Eventually, it is a matter of satisfying accomplishment fields. A better and lasting with other relations is seen by managers as a less important effect; this creates a legitimation gap concerning real authority and chain-partnerships. The outcome is considered to be important, but generally speaking, one is not familiar with the methods that are necessary for that.

\section{References}

[1] Collins, J. 2004. Good to Great. Amsterdam/Antwerpen: Business Contact.
[2] Hardjono, T. W. 2010. Ketensamenwerking. Leerdam: C3 Group. (in Dutch)

[3] Keeris, W. G., and Keeris MRICS. 2001. Vastgoedbeheer Lexion. Wolters: Noordhof Groningen. (in Dutch)

[4] Hardjono, T. W. 1995. Ritmiek en Organisatiedynamiek. Vierfasenmodel. Dissertation thesis, Erausmus University. (in Dutch)

[5] Wetenschappelijke Raad voor het Regeringsbeleid. 2004. Bewijzen van een Goede Dienstverlening. Amsterdam: Amsterdam University Press. (in Dutch)

[6] Lievegoed, B. J. C. 1993. Organisaties in Ontwikkeling. Zicht op de Toekomst. Rotterdam: Lemmiscaat Rotterdam. (in Dutch)

[7] Dingemans, G. D. J. 2005. De stem van de Roepende. Pneumatheologie. Kampen: Uitgeverij Kok. (in Dutch)

[8] Schaar, J. van der. 2010. "Benchmarking en Visitatie: Enkele Inleidende Opmerkingen.” Presented at Inleiding op het SOMcongres, April 8, 2010, te Utrecht. (in Dutch)

[9] Luyn, A. H. van. 2008. "Reactie op de Presentatie van het boek 'Verbindend Bouwen. Over Solidariteit en Verzorgingsstaat'." Prestented at Christelijk Sociaal Congres, August 28, 2008. (in Dutch)

[10] Wetenschappelijk Instituut voor het CDA. 2005. Investeren in de Samenleving. Een Verkenning naar Missie en Positie van de Maatschappelijke Onderneming. Den Haag: WI. (in Dutch)

[11] Sociaal Economische Raad. 2000. De winst van Waarden. Den Haag: SER. (in Dutch)

[12] Balkenende, J. P., Kaptein, M., Kimman, E., Van den Toren, J. P., and Hardjono, T. W. 2003. Onderneming \& Maatschappij. Op Zoek naar Vertrouwen. Assen: Koninklijke Van Gorcum. (in Dutch)

[13] Jagersma, P. J. 2003. Waarden en Waarde. Breukelen: Universiteit Nyenrode. (in Dutch)

[14] Os, P. Van. 2009. Dienen en Verdienen om te Dienen. Paper ASRE seminar. (in Dutch)

[15] Veuger, J. 2014. "Materieel Immaterieel. Besturing van Woningcorporaties in Samenhang Metmaatschappelijke Waarden.” Dissertation thesis. Rotterdam: RSM Erasmus Universiteit Rotterdam. (in Dutch) 